DOI: $\underline{\text { https://doi.org/10.17648/2238-037x-trabedu-v29n1-20620 }}$

(c) (1) https://creativecommons.org/licenses/by/4.0/

\title{
O PAPEL DA UNIVERSIDADE É ENSINAR A PENSAR BEM
}

The role of university is to teach think

\author{
Entrevistado \\ Joaquim Luís Medeiros Alcoforado \\ Entrevistadores \\ Carlos Roberto da Costa ${ }^{1}$ \\ José Geraldo de Oliveira²
}

\section{RESUMO}

A entrevista aborda temas como a educação continuada, baseada na pedagogia das cinco escolas da vida, de Jan Amos Comenius (1592-1670); a missão da universidade ao longo do tempo; a inclusão das ciências da engenharia e matemática após a reforma de Leibniz (1646-1716), na universidade de Hannover; da autonomia como instituição; a formação holística num mundo em contínua mudança; os desafios da era digital; o aporte de Luc Ferry e de Paulo Freire; o papel da universidade em ensinar a pensar.

Palavras chave: Educação. Reforma. Autonomia. Formação. Pensar.

\section{RESUMEN}

La entrevista aborda temas como la educación continua, basada en la pedagogía de las cinco escuelas de la vida, de Jan Amos Comenius (1592-1670); la misión de la universidad a lo largo del tiempo; la inclusión de la ingeniería y las ciencias matemáticas después de la reforma de Leibniz (1646-1716) en la Universidad de Hannover; autonomía como institución; entrenamiento holístico en un mundo en constante cambio; los desafíos de la era digital; la contribución de Luc Ferry y Paulo Freire; El papel de la universidad en la enseñanza de cómo pensar.

Palabras clave: Educación. Reforma. Autonomía. Formación. Pensar.

\section{ABSTRACT}

The interview addresses topics such as continuing education, based on the pedagogy of the five schools of life, by Jan Amos Comenius (1592-1670); the university's mission over time; the inclusion of engineering and mathematical sciences after Leibniz's reform (1646-1716), at the University of Hanover; autonomy as an institution; holistic training in a constantly changing world; the challenges of the digital age; the contribution of Luc Ferry and Paulo Freire; the role of the university in teaching how to think.

Keywords: Education. Remodeling. Autonomy. Formation. Think.

\footnotetext{
${ }^{1}$ Jornalista formado pela Faculdade Casper Líbero, Mestre e Doutor pela ECA - USP, tem Pós-doutorado pela FFLCH da Universidade de São Paulo. É professor do PPGCOM da Faculdade Cásper Líbero. E-mail: ccosta@casperlibero.edu.br

${ }^{2}$ Bacharel em Publicidade e Propaganda pela Unisa, é Mestre em Ciências da Comunicação pela Faculdade Cásper Libero e Doutor em Ciências da Comunicação pela Universidade Autônoma de Barcelona. É professor na Universidade Paulista, UNIP. E-mail: zegera@hotmail.com
} 
Joaquim Luís Medeiros Alcoforado, doutor em Ciências da Educação, focado em Educação Permanente e Formação de Adultos. É professor da Faculdade de Psicologia e de Ciências da Educação da Universidade de Coimbra, foi Coordenador do Mestrado em Educação e Formação de Adultos e Intervenção Comunitária, é Coordenador do Mestrado em Ciências da Educação e integra a Comissão de Coordenação do Doutoramento em Ciências da Educação. No dia 23 deste janeiro de 2020, ele nos recebeu com cordialidade em seu gabinete em Coimbra. "Me chame apenas de Luís Alcoforado", disse ao se apresentar. Luís esteve já algumas vezes no Brasil, participando de bancas de doutorado e, recentemente, ao longo do último ano, ministrando palestras no SEMESP, na UERGs, em Osório, na UFMA, em São Luís e Pinheiro, na UFPE, em Recife e Caruaru, na UFPI, na UNEB, no IFRN e orientando seminários nos cursos de pós graduação da UFRS e UFPR. Na conversa que mantivemos, foram muitos os temas, do "diploma com prazo de validade a vencer", daí a necessidade da educação contínua; sobre a missão das instituições universitárias; sobre a autonomia desses centros de educação; a formação holística num mundo em que estamos dentro da mudança; nos desafios da sociedade 4.0. Leitor profícuo de Paulo Freire, Luís Alcoforado aborda ainda a chegada do Sociedade 5.0, movimento com gestação iniciada no Japão.

Entrevistadores: Em uma das palestras que o senhor ministrou o tema foi o da educação continuada. O senhor estava dizendo que o diploma tem um prazo de validade, se não continuarmos estudando seremos carta fora do baralho?

Joaquim Luís Medeiros Alcoforado: Esta é minha área de estudo, portanto não posso fugir e nem seria o caso, dando uma opinião menos descomprometida, sendo uma área a que me dedico faz muitos anos. Por isso, buscarei um equilíbrio entre o que é uma opinião mais descomprometida das referências e dos estudos e o que é resultado daquilo que a gente vai pensando e escrevendo. Se quisermos encontrar algum consenso entre as pessoas que pesquisam e publicam sobre educação, esse consenso gira em torno desse equilíbrio: a educação inevitavelmente se prologa ao longo de toda a vida e se alarga a todos os espaços da vida. E isso não é uma ideia nova. No livro Pampaedia, o presbítero, educador e reformador protestante Jan Comenius (1592-1670) dizia exatamente isto: para atender às necessidades a que educação já então deveria responder teríamos de pensar em oito escolas ao longo da vida, começando com uma escola, que ele chamava de pré-natal, ou seja, antes do nascimento e terminando apenas com a escola da morte ${ }^{3}$. Sendo ele um cristão da reforma, entendia que tínhamos de nos preparar para a viagem final. Comenius é, assim, o iniciador do pensamento pedagógico contemporâneo - ou, se preferir, moderno, indo ao ponto de considerar que cada uma dessas escolas deveria ter uma especificidade e caraterísticas muito próprias.

Entrevistadores: Onde e quando esse pensamento começa a ganhar forma?

Joaquim Luís Medeiros Alcoforado: Uma educação ao longo e em todos os espaços da vida, no caso da Europa, afirma-se, ganhando foros de política pública, com a emergência do liberalismo. Os liberais e os republicamos acreditavam que a educação era uma espécie de "abre-te sésamo" para o novo mundo. As pessoas educadas iriam forçosamente exigir

\footnotetext{
${ }^{3}$ Em seu livro Cultura Popular na Idade Moderna, Peter Burke analisa a importância das publicações do que se convencionou chamar "Ars Moriendi" - como o livrinho Combate Espiritual (1589), que teve 23 edições até 1788, apenas na França. Ou o Pensez-y-bien, o mais popular de todos, com altas tiragens. Burke reforça a importância da Reforma na alfabetização: ainda no século XVII a Suécia tinha mais de $90 \%$ da população rural sabendo ler.
} 
melhores condições de vida e, depois, outras condições políticas. A questão é que no século XIX e início do século XX, quando pensávamos uma educação para jovens e para adultos, era sempre como uma segunda oportunidade para as pessoas que não tinham frequentado a escola. E por razões de desenvolvimento, primeiramente, econômico e depois social e cultural. Depois, por questões políticas que o liberalismo e a ética republicana acabaram por colocar no centro da discussão, sempre se acreditou que as pessoas pudessem interpretar e debater as informações e os temas que atravessavam o seu dia a dia, tendo essa obrigação para poder participar naquilo que começava a ser a consagração de formas democráticas de governo e gestão da coisa pública. Dito de outra forma, consagrou-se a ideia de que um investimento nas escolas, educando crianças e adolescentes seria inevitável para construir, no futuro, melhores sociedades, mas se quiséssemos introduzir melhorias imediatas nas sociedades atuais, essas mudanças só poderiam advir dos contributos das populações adultas. Como não há mudanças sem novas aprendizagens e sem as envolver em experiências educativas adequadas, um investimento em educação de jovens e adultos era inevitável. O período pós Segunda Guerra Mundial veio exatamente consagrar essa ideia e estas propostas. Levando ao tal consenso sobre a inevitabilidade da educação (formal, não formal e informal) se prolongar a qualquer idade e espaço da vida.

\section{Entrevistadores: Tornando claro que há um limite para a validade do diploma?}

Joaquim Luís Medeiros Alcoforado: Sim. Por exemplo, se nos anos 1960 um engenheiro eletrotécnico terminasse os estudos universitários e não mantivesse contato com a área de formação e, cinco anos depois, ingressasse no mercado de trabalho em eletrotécnica, $40 \%$ do que havia aprendido não lhe serviria para nada. Hoje podemos falar disso da seguinte maneira: por razões epistemológicas, por razões profissionais, tecnológicas e culturais temos de continuar a nos envolver em atividades educativas ao longo da vida. Claro que as políticas públicas, influenciadas por um paradigma ainda socioeconômico, acabam por se orientar predominantemente para o período da vida ativa das pessoas. Mas, hoje, cada vez mais esse paradigma evolui para o da necessidade de promover um "envelhecimento ativo". Tivemos, na França ${ }^{4}$, na década de setenta do século XX, por exemplo, um educador que pensou e que criou a primeira Universidade da Terceira Idade. O motivo que ele apresentava era simples: "O que iremos investir nessas universidades, vamos poupar em medicamentos e em investimentos em saúde". Obviamente, para este entendimento, o melhor modo de garantir um investimento saudável, sem patologias, é manter as pessoas ativas mental e fisicamente. Portanto, são razões como esta que têm vindo a consolidar o consenso à volta da educação continuada.

\section{Entrevistadores: E há ainda o aprendizado da vida.}

Joaquim Luís Medeiros Alcoforado: Exato. Muito do que aprendemos e é fundamental em nossa vida acontece fora da escola, dos espaços formais do ensino. Aprendemos no trabalho, vendo televisão, com os amigos... Portanto, quando falamos em políticas educativas temos de pensar não apenas em criar condições para que nossas crianças, jovens e adolescentes aprendam conteúdos de áreas disciplinares consideradas essenciais, mas levar em conta que eles precisam de mais tempo de formação, apreendendo mais coisas e diversificando as experiências educativas, até para ser mais autodirigidas, mais ativas e mais críticas, no futuro. A continuidade dessas experiências educativas supõe "enriquecer os diferentes espaços de vida" de modo a torná-los mais desafiantes. Pois enquanto houver esta continuidade, com jovens lendo, indo ao cinema, discutindo com os colegas, enquanto tivermos adultos em espaços de trabalho e de vida mais desafiantes do

\footnotetext{
${ }^{4}$ Pierre Vellas, presente no livro Le troisième soufflé, que descreve toda a história da trajetória de criação da primeira Universidade da Terceira Idade, em Toulouse na França.
} 
ponto de vista intelectual, estarão motivados na busca do conhecimento. Essa é a questão a se colocar na educação nas políticas educativas: ter boas escolas. Quando se afirma que a educação se prologa por toda a vida, os desafios da escola se tornam ainda maiores: serem capazes de transferir a herança cultural das gerações adultas de forma disciplinar, sequencial e hierarquizada, mas sendo igualmente capazes de proporcionar um conjunto de experiências relacionais, trabalhos de pesquisas, de grupo, de construção de uma inteligência emocional que permita aos discentes essa continuidade temporal/espacial das experiências e atividades de aprendizagem. E essa é uma missão não apenas da escola. Mas da comunidade, da cidade: oferecer a todos os cidadãos a oportunidade de se desafiarem, de "experienciar", claro, tudo isso com os valores que as sociedades aceitam como basilares, do que desejam para si próprias.

Entrevistadores: Sobre a criação das universidades, houve dois movimentos: num, os alunos se juntavam para pagar um professor, como foi o modelo da Itália; do outro, os professores se associavam para oferecer cursos, como no caso de Paris.

Joaquim Luís Medeiros Alcoforado: Em relações à universidade, a questão é outra [respira... tosse, pigarreando]. No último mês de outubro num fórum sobre ensino superior, promovido pelo SMESP, em São Paulo, fui desafiado a, partindo de uma síntese da história das Universidades (em particular as europeias e, ainda mais em particular olhando para os 730 anos da minha Universidade) falar sobre o que me parece dever ser, atualmente, a missão da Universidade. Então, as universidades europeias surgiram como comunidades acadêmicas que tinham autonomia, como a de buscar formas de financiamento que as afastavam um pouco dos poderes políticos instituídos. Claro que os reis desempenharam papel importante, como aqui em Portugal na formação da Universidade de Coimbra, mas eles apenas davam privilégios à universidade, sem assumirem o essencial do seu financiamento. Esses privilégios permitiam algum tipo de rendimento para se manterem. A corte entendia a necessidade de formar acadêmicos, mas a preparação para a universidade praticamente inexistia. Por isso que as universidades tinham estudos gerais e depois estudos mais direcionados. Daí foram aparecendo universidades com diferentes características. Umas por privilégios reais, outras por força da própria comunidade. Em alguns casos, as aulas de um professor eram tão famosas que um grupo se juntava para fundar e desenvolver uma universidade. Em outro caso, como a Universidade de Cambridge e a de Oxford, é um típico exemplo: parte da comunidade se afasta da primeira para formar a segunda. Importante é observar que qualquer universidade era uma comunidade com autonomia, mas destinada sempre a contribuir para o engrandecimento da cristandade.

\section{Entrevistadores: Como assim?}

Joaquim Luís Medeiros Alcoforado: Porque só era universidade quando o papa outorgava, através de uma Bula, o direito dessa escola à universalidade. Depois, as universidades evoluíram exercendo influência e sendo influenciadas pelas dinâmicas sociais e políticas da região em que estavam instaladas. Veja o caso da Reforma. As universidades acabaram por ser colocadas ao serviço desse movimento, havendo necessidade de as reorientar completamente, o que se tornou algo doloroso e demorado. $O$ fato de as universidades irem crescendo em área de conhecimento também não se constituiu como um processo pacífico. As escolas medievais, para a formação dos acadêmicos, contavam com três tipos de ciências: a) a ciência do homem para o homem e para a natureza, que era a medicina e a filosofia; $b$ ) a ciência dos homens para os outros homens, que era o direito civil e canônico; e c) a ciência do homem para Deus: a teologia. Isto era o que as universidades consideravam fundamental e digno do estatuto de disciplina universitária. O Renascimento trouxe outras disciplinas, como a linguística, a história, enquanto os séculos XVII e XVIII vão consagrando o ensino das ciências da natureza. Mas nem sempre foi completamente pacífico aceitar essas novas disciplinas, como não foi pacífico, por exemplo nas 
universidades francesas e até na portuguesa que áreas novas como a engenharia ganhassem o estatuto de ciência e disciplina universitária, dentro das escolas com uma história mais longa. Até hoje há na França as Écoles Polytechniques, que são por excelência a escola de formação de engenheiros. Universidades tradicionais como Coimbra ou Salamanca foram revelando muitas dessas hesitações e dificuldades.

Entrevistadores: $E$ logo depois veio o lluminismo...

Joaquim Luís Medeiros Alcoforado: Que foi outro processo algo doloroso, quando o Estado decide que a partir daí a universidade era de sua responsabilidade. Então se era verdade que desde o início os reis concediam privilégios, pois precisavam de físicos (médicos) e, para contribuir para a alta administração, demandavam bacharéis em Direto, de teólogos para interpretar as Escrituras e do Direito Canônico, esclarecendo dúvidas sobre os créditos papais, algo premente em um país católico, para auxiliar o rei no modo como tudo isso se traduzia nas decisões do dia a dia do Estado. O fato é que no iluminismo, entre os séculos XVIII e XIX, passou-se a pensar que as universidades eram centrais para 0 desenvolvimento dos países, dos "Estados-nação". Mais uma vez Coimbra constitui um exemplo bem significativo deste movimento. O Marquês de Pombal, no início da segunda metade do século XVIII, deslocou-se à cidade, acompanhado de um aparato militar algo intimidatório, para que a "reforma pombalina" empreendida em sua representação pelo Bispo e Reitor Francisco de Lemos (nascido no Rio de Janeiro) não tivesse contratempos de maior. E a reforma interferia com todos os aspetos da vida e do ensino, da Universidade. Outra questão interessante é que as universidades demoraram muito tempo em considerar uma área que hoje é absolutamente central e talvez uma das mais importantes, atualmente, nos diversos parâmetros de avaliação de qualquer universidade, que é a pesquisa. Foi apenas no século XVIII que uma universidade na Alemanha introduz nos seus objetivos a pesquisa como uma das suas atividades principais. Mas, como sabemos, ainda ao longo de todo o século XIX as instituições mais reconhecidas e envolvidas na pesquisa eram as sociedades científicas. Portanto as universidades, nas suas dinâmicas internas e contextuais, foram seguindo uma evolução lenta, natural, ainda que muitas vezes imposta do exterior, com sucesso nem sempre completamente conseguido.

Entrevistadores: O senhor se refere à reforma de Alexander von Humboldt?

Joaquim Luís Medeiros Alcoforado: No caso me refiro à Universidade de Göttingen, bem no centro da Alemanha, onde pela primeira vez se enuncia como principal objetivo a necessidade de as universidades conciliarem a pesquisa e o ensino, adotando a pesquisa como um dos tripés dos pilares de sua missão, como atualmente a reconhecemos: ensino, pesquisa e extensão.

Entrevistadores: Foi no século XX que as universidades atingiram o ápice desse tripé? $E$ como elas se ajustam à sociedade 4.0 ?

Joaquim Luís Medeiros Alcoforado: No fundo o que quis dizer na minha palestra de São Paulo é que as universidades, aliás, isso é dito por uma pessoa que é mais reconhecida, não em nossa área, mas na da poesia, de que ele é um dos grandes do século XX, Rómulo de Carvalho ${ }^{5}$. Ele escreveu um livro muito fundamental História do Ensino em Portugal, desde a fundação da nacionalidade até ao fim do regime de Salazar-Caetano [de 1986]. Talvez seja o livro que melhor sistematiza a história do ensino em Portugal. Ele trata da questão

\footnotetext{
${ }^{5}$ Professor de química e física no ensino secundário, Rómulo Vasco da Gama de Carvalho (1906-1997) foi um divulgador do estudo das ciências. O dia de seu nascimento, 24 de novembro, é o Dia Nacional da Cultura Científica, em Portugal. Sob o pseudônimo de António Gedeão, publicou poemas como A Pedra Filosofal e Lágrima de Preta.
} 
universidade e escreve que nunca conseguimos entender essa instituição, sem percebermos que sempre esteve vinculada a uma certa concepção do ser humano, seja contribuindo para o engrandecimento do cristianismo; ou após as reformas iluministas a serviço do desenvolvimento econômico, ou socioeconômico, quando muito. A questão que se coloca hoje é se com mudanças tão acentuadas ainda cabe falar em paradigma econômico e social, se vale a pena continuar pensar na formação de pessoas para aumentar a produtividade e competitividade dos grandes grupos - mesmo buscando humanizar e criar condições para que a competitividade ocorra no âmbito de um conjunto de valores humanistas. A questão do 4.0 acentua uma lógica quantitativa e um tanto gerencialista que eu, mesmo não a recusando liminarmente, vejo com desconfiança. Se observarmos os critérios utilizados para avaliar as universidades, nos rankings internacionais mais reconhecidos, temos números de publicações, patentes - e estamos falando de patentes com valor tecnológico, gerando empregabilidade dos diplomados, moradores da região em que a universidade está. Sabemos que é preciso criar riqueza, que as universidades não podem estar dissociadas desse esforço. O desafio que se coloca, e fui buscar esta ideia, primeiro às reflexões da Escola de Frankfurt, depois porque atravessa todo o pensamento de Paulo Freire e, mais recentemente, porque a reencontrei nos escritos entusiasmantes de um filósofo francês que continua escrevendo muito bem, Luc Ferry 6 e que desde o livro Homo Aestheticus - $A$ Invenção do Gosto na Era Democrática, retoma a necessidade de continuarmos a procura de uma nova ética com o belo como orientação central. A frase que melhor traduz todo este movimento, normalmente atribuída a Walter Benjamim e com que eu terminei a minha palestra em São Paulo, pode enunciar-se assim: "o belo é difícil, mas é o único caminho". E, então, depois do homo christianus, do homo economicus (e socialis) e homo digitalis, talvez a ideia de homo aestheticus seja capaz de articular as preocupações mais recentes, com os desafios de natureza mais cultural, como escreveu Alain Touraine ${ }^{7}$, construindo um mundo progressivamente impregnado de maior boniteza, pela recusa, sem tibiezas, de todas as formas de injustiça, descriminação, guerra, pobreza...

\section{Entrevistadores: Seu conceito do trabalho na era pós-industrial traz à cena o que vivemos} hoje.

Joaquim Luís Medeiros Alcoforado: Pensando na indústria 4.0 e antecipando a 5.0 (já circulam textos sobre ela), diríamos que as pessoas mais preparadas seriam as da era digital que não só consigam lidar com os desafios que ela nos coloca, mas que consigam desenvolver a capacidade e formas de ação tendentes a influenciar o essencial das ideias que a atravessam. A universidade tem de criar condições para preparar os discentes para essa era digital e para a economia e a cultura digitalizadas, em que o novo espaço de vida é também, inevitavelmente, formativo: o ciberespaço. Sabemos que o ensino só é superior porque garante aos seus alunos a aprendizagem do que de mais atualizado existe nas diferentes áreas de saber. Para além disso, teremos de buscar algo que, quer em termos pessoais, quer nas diferentes comunidades de pertença, nos envolva na procura de objetivos comuns de progressivo bem-estar. Essa ideia se inspira na referida frase de Walter Benjamin, e nos contributos também já referidos de Luc Ferry quando distingue entre o gosto e o belo.

\footnotetext{
6 Nascido em 1951, estudou na Universidade de Paris e em Heildelberg. Doutor em Ciência Política, foi ministro da Educação, de 2002 a 2004. Publicou nada menos que 24 livros, alguns em formato transmídia. Entre eles, destacam-se "A Nova Ordem Ecológica", de 1992, com o subtítulo "A árvore, animais e seres humanos"; "L'Homme-Dieu ou le sens de la vie", de 1996, "Aprender a Viver: Tratado de filosofia para uso das jovens gerações", de 2006, e "7 lições para ser feliz" (2019).

7 Alain Tourraine (França, 1925) é um sociólogo do mundo do trabalho e dos movimentos sociais, conhecido por ter cunhado a expressão "sociedade pós-industrial". A referência que aqui se faz lembra o livro Un nouveau Paradigme.
} 
Gosto não se discute. Temos diferentes times de futebol, gostamos de cores distintas, usamos roupas diferentes, senão andávamos todos iguais [risos]. $O$ belo resulta de uma conciliação de interesses, da aceitação alargada das pessoas sobre o que pode ou não ser os contornos gerais de uma obra de arte, de uma sinfonia. $E$ isso se prolonga no tempo por ser algo ruminado por uma comunidade abrangendo muitas pessoas e num processo contínuo. Nesse sentido, o belo é muito mais uma construção da sociedade. Também podemos fazer o contrário, construir o belo pela recusa do horrível. Na lógica de Luc Ferry pensar seria assim: quando vejo a fotografia de uma criança depois um bombardeio na Síria, isso tem de ser horrível para todos. Há coisas que todos temos de abominar. É urgente que todos se conscientizem de que é preciso recusar o horrível, pois fere a humanidade e tudo o que foi consensualizado ao longo do século XX, como os direitos humanos. Paulo Freire também falou sobre isso: "A educação deve ter duas balizas, a ética e a estética - ou, como ele dizia também, a decência e a boniteza. A educação se diferencia da aprendizagem por ser uma mistura de saberes e valores. Conhecimento e valores que nos orientam num determinado sentido em termos individuais e de sociedade. Do outro lado, esta boniteza, como diria Paulo Freire, a estética é colocada como meta, pois é possível uma sociedade sempre mais bonita ou a caminho do belo pela recusa do horrível. A universidade tem o múnus de preparar as pessoas para uma economia, que neste momento é digital, mas também precisa da antena aberta para os desafios da economia 5.0, colocando a economia, o desenvolvimento e as mudanças culturais a serviço de todos os cidadãos e cidadãs, conscientizando que é possível construir em conjunto uma vida que descarte os horríveis que irão aparecendo. É ela, a universidade, o único espaço em que se pode realizar isso de forma desinteressada.

\section{Entrevistadores: $E$ isso o que acontece hoje com a academia?}

Joaquim Luís Medeiros Alcoforado: Os já referidos indicadores utilizados para avaliar as universidades podem levar a um "condicionamento" caso se centrem em um conjunto de preocupações e respostas mais imediatas, quando sua vocação natural é, como escreveu Olivier Reboul, o estudo e a compreensão. Contribuir para melhores sociedades, mais orientadas pelo belo, nos obriga a um estudo desinteressado e de longo prazo. Um exemplo: quando alguém na rua me pergunta onde fica a rua $X$ e respondo que fica ao fundo, à direita, isso é um saber imediato, o de localizar. Nas universidades não existe nem isso. Elas ensinam a ler mapas, agora a usar GPS e a procurar novas formas de otimizar a orientação para bem das pessoas e dos seus contextos. Buscar informações e ser críticos em relação a elas, esse é um saber de longo prazo, argumentado, e tem de ser desinteressado, sem ligação com interesses econômicos imediatos. Minha preocupação com os indicadores usados nas avaliações das Universidades é a exigência de criar patentes, respostas, financiamentos, que nos associa a uma lógica imediatista, contraria à filosofia da própria universidade.

Entrevistadores: O pesquisador brasileiro Carlos Henrique de Brito Cruz, disse numa entrevista publicada na revista Diálogos\&Debates, que se a universidade estivesse apenas voltada para o mercado, ele não teria feito a graduação em Engenharia Eletrônica no Instituto de Tecnologia da Aeronáutica (ITA) em 1978, nem teria sido criada a Embraer (Empresa Brasileira de Aeronáutica).

Joaquim Luís Medeiros Alcoforado: Que a universidade forme pessoas com capacidades de inovação, isto é bom e indispensável, mas para isso precisa, como se disse, uma boa formação de base nas diferentes áreas cientificas e tecnológicas. $O$ peso específico da universidade vem da formação e da pesquisa realizada de modo desinteressado e a longo prazo, com saberes argumentados, por estar inserida em uma comunidade em que a discussão é um modo natural de trabalho. Desde a ldade Média, quando se fala da autonomia é exatamente essa possibilidade de discutir as questões abertamente. Se a 
formação que proporcionamos for resultado disso, estamos a formar pessoas, em diferentes áreas, com saber tecnológico e científico de ponta. Nosso egresso deverá, também, ter capacidade de trabalhar em conjunto, com a dimensão solidária com o outro, com a sociedade, com a espécie humana. Em consequência, inovará em sua área específica, seja na área tecnológica, social, cultural. Esse é o papel da universidade: pensar e ensinar a pensar, assumindo um programa epistemológico plural, conjugando dinamicamente o contributo de ciências empírico-analíticas, histórico-hermenêuticas e críticas.

Entrevistadores: Penso na sua reflexão sobre Parmênides e Heráclito.

Joaquim Luís Medeiros Alcoforado: É um consenso das últimas décadas de investigação na psicologia do desenvolvimento, o de que mudamos ao longo de toda a vida, num processo contínuo, mutttirreferencial, de ganhos e perdas. Pior seria se em função de uma experiência educativa que a universidade proporcionasse às pessoas, elas não se transformassem também, profundamente, em termos pessoais. Veja bem: se eu estivesse preparando para o mercado de trabalho que consigo identificar agora, e ainda que fizesse isso muito bem, 0 problema é que quando os alunos que preparo chegarem ao mundo do trabalho nem eles são os mesmos e nem o mercado. Por isso, a ideia é: não podemos e nem devemos de forma leniente abdicar dessa formação, primeiro a proporcionada pelas experimentações que vão além da formação científica e tecnológica, depois, a formação técnica que os discentes escolheram para seu aprendizado, com a visão aberta, capaz de compreender 0 mundo. Quando falamos de estudo e compreensão, isso traduz entender e ser capaz de agir, interferir e transformar a sociedade em acordo com o conjunto de valores que corporiza o tal entendimento de ser humano. Disso a universidade não pode nunca abdicar.

Entrevistadores: Ouvi pela primeira vez a referência à sociedade 5.0, feita pelo senhor há pouco.

Joaquim Luís Medeiros Alcoforado: Esse é um movimento, que apareceu recentemente no Japão, e vem desafiar a revolução 4.0 para incluir as pessoas no jogo. Pensamos em uma indústria inevitavelmente digital e a indústria 4.0 evidencia isto. Não há como contestar: toda a atividade econômica, social e cultural, depende hoje do recurso digital. A inteligência artificial e internet das coisas atravessam nossa vida e, tendo consciência disso, o desafio da sociedade 5.0 será como agarramos tudo isso para direcionar ao benefício dos cidadãos, em seu desenvolvimento e realização pessoais e grupais. Esse é o grande desafio que enfrentaremos a seguir.

\section{Entrevistadores: $O$ senhor está falando em renda única universal?}

Joaquim Luís Medeiros Alcoforado: Não apenas, mas traduz um conjunto de questões que há a obrigação de levar aos dirigentes e a quem produz conhecimento. No processo de decisão das dimensões econômicas, sociais e culturais, é imperativa a obrigação de criar melhores condições, bem-estar e qualidade de vida para todas as pessoas, onde quer que estejam.

Entrevistadores: O senhor é um professor ajustado ao perfil do docente hoje: formou-se no mundo analógico e ensina no mundo digital. Vê resistência em seus colegas?

Joaquim Luís Medeiros Alcoforado: Não sei se há resistência, mas preparados, em geral, ainda não estamos. Nunca estamos [risos] porque a vida sempre é mais rápida. Se me perguntar quais são as instituições que mais prestígio alcançaram ao longo dos anos da modernidade, as escolas e as universidades com certeza estão lá. Por mais críticas que façamos às escolas, são instituições que souberam cultivar e ganhar reconhecimento ao longo desse período. Portanto, é difícil afirmar que instituições reconhecidas e prestigiadas têm de se repensar a si mesmas; além do mais os professores são pessoas adultas e sabem que mudanças mais profundas, nas pessoas adultas, exigem, muitas vezes, o envolvimento 
volitivo em processos transformativos mais complexos. A questão é que somos a soma de muitas experiências, de socialização muitas vezes acrítica e até inconsciente, pois aprendemos em todos os momentos e espaços da vida. Se sou o resultado disso tudo, mudar exige a capacidade de pensar sobre mim mesmo, sobre a vida, sobre os contextos e muitas das vezes nem temos tempo [risos] porque as dinâmicas que as instituições nos exigem vão sendo moduladas em um determinado sentido que sequer nos permite 0 confronto conosco mesmos para exigir mudanças. Mas as pessoas sentem a urgência de trabalhar de outra maneira, utilizar novos recursos. Não aposto em grandes rupturas, de chegar na universidade e estalar os dedos ou acender a luz e colocar todas as pessoas para trabalhar na cultura digital. Aos poucos iremos pensar e trabalhar de outra maneira.

Entrevistadores: Esse é outro aspecto preocupante, a lentidão.

Joaquim Luís Medeiros Alcoforado: Muitos alunos têm esse domínio muito fácil, pois são nativos digitais, e nos deixam receosos para ousar em experiências educativas. Não será fácil. As escolas de prestígio por haverem formado pesquisadores em uma determinada cultura, não irão economizar esforços para empreender e provocar a mudança, mas se esperarmos uma revolução da noite para o dia, correremos o risco de alguma desilusão. Como a história também nos ensinou, as instituições não mudam profundamente por imposição legislativa ou por uma decisão de seus dirigentes, será mais em resultado de um processo contínuo de trabalho colaborativo que envolva todos e todas num questionamento responsável e não intimidatório das práticas e na procura de novos caminhos a empreender.

Entrevistadores: No Brasil, há certa confusão entre o aprendizado e o discurso de formar para a empregabilidade, resultando até numa política do governo visando a uma formação mais técnica e menos humanística.

Joaquim Luís Medeiros Alcoforado: Discuto muito isso com meus colegas. Se queremos, e no ensino público aqui isso é muito claro, formar cidadãos com saberes que a sociedade assume como seus, para que todos tenham as mesmas oportunidades, direitos e deveres, tem de ser resultado de uma discussão alargada traduzida em políticas públicas de ampla aceitação. De fato, a educação é responsabilidade do Estado em preparar cidadãos com os saberes necessários para que todos tenham essas mesmas chances e que os valores a trabalhar sejam fundamentais para a sociedade em que a escola se insere, criando sociedades mais justas e melhor administradas (afinal era a isto que Aristóteles chamava cidadania). Por isso mesmo, foi uma escolha minha que meus filhos estudassem em escolas públicas, contribuindo eu próprio para reforçar a exigência às escolas públicas para construírem uma formação de base que eu considero indispensável que seja comum para todos. Já em relação ao ensino superior, ainda que defenda que ele seja predominantemente público, também concordo com a existência de projetos educativos privados, a que as famílias e a economia possam recorrer, para satisfazer intenções mais direcionadas, sem deixarem de responder pela sua inclusão nos princípios orientadores do bem comum. No Japão, por exemplo, havia a tradição de que grandes empresas só recrutavam ou tinham ligação preferencial com determinada universidade. Até porque a socialização profissional no Japão não se fazia tanto pela profissão como pela ligação que as pessoas têm com a empresa em que trabalham. Mas a universidade, qualquer universidade, deve ter sempre como objetivo, além da preparação para o mercado de trabalho, obrigação de uma formação mais holística. Edgar Morin tem um texto que acho fundamental "Sete saberes para a Educação do Futuro", no qual defende que a formação das pessoas precisa ter sempre como base um modo equilibrado como o de um triângulo em seus três vértices. No primeiro desses vértices ele coloca a pessoa: a educação tem de permitir à pessoa sua realização plena, construir os projetos de vida, descobrir os talentos, de se sentir bem; no segundo ele destaca, a sociedade: sendo que pessoas realizadas têm obrigação de contribuir para melhores sociedades. Não é possível obter realização profissional indo contra das expectativas e 
objetivos da comunidade, assim como a satisfação profissional deve ocorrer no contexto de uma sociedade em harmonia e dando suporte à realização de todos, procurando, então, não supervalorizar a dimensão pessoal em detrimento da comunidade, nem a dimensão da comunidade em detrimento da realização das pessoas. Esse contexto de equilíbrio é ainda garantido com o compromisso de que cada pessoa e a sociedade que integra deverão ter, em conjunto, para com a espécie humana - defendendo um futuro sustentável, com todos e por muito mais tempo. Desta forma, a ideia deverá sempre passar por formar pessoas de um modo holístico, descobrindo e valorizando seus talentos e ao mesmo tempo seu pertencimento a uma sociedade solidária, pois estudaram o mundo e podem compreender o que seja um mundo melhor. Me referia a isso quando falei do homo aestheticus e essa é uma das metas centrais da universidade. Por isso, o Estado não pode abrir mão da rede de universidades públicas, em cuja autonomia não deve interferir, mas garantir a qualidade das condições para exigir a qualidade do trabalho, alinhado com os princípios enunciados.

\section{Entrevistadores: $O$ senhor é um utópico?}

Joaquim Luís Medeiros Alcoforado: Não. Ainda que me pareça importante conduzirmos a nossa vida pela procura do inexistente, acreditando que isso pode resultar muito mais em função da construção de conhecimento e da luta contínua pela construção de novas realidades. Na década de trinta do século XIX, Jules Michelet, na Introdução da famosa História de França, lembrava que a história da humanidade é uma luta prometaica pela liberdade humana, que os humanos travam, desde sempre, para se livrarem de constrangimentos naturais e das falsas crenças. É assim que eu vejo o meu papel de Professor, na minha Universidade e é essa ideia que tento passar aos/às meus/minhas alunos/as. Por vezes eles também me olham desconfiados/as e também me perguntam se algumas das nossas propostas não têm algo de utopia. Nesses momentos respondo a turmas esmagadoramente compostas por jovens mulheres: "Se vocês vivessem há cem anos atrás não estariam aqui na universidade". Se elas estão ali agora é porque alguém lutou muito para que isso acontecesse e tornou isso possível, quando uma esmagadora maioria não acreditava. Queiramos ou não, o mundo está em constante mudança, não há alternativa. Qual é a proposta? A de estarmos dentro da mudança. Esse é o desafio 4.0 e do 5.0. Vamos colocar assim: o mundo está sempre a mudar. O que nos desafia o 4.0 e o 5.0? É estar dentro da mudança. E ser capaz de dar o sentido que desejamos a essa mudança!

Data da submissão: 14/05/2020

Data da aprovação: 18/05/2020 